\title{
Open-Mouthpiece Ventilation Versus Nasal Mask Ventilation in Subjects With COPD Exacerbation and Mild to Moderate Acidosis: A Randomized Trial
}

\author{
Antonello Nicolini MD, Mario Santo MD, Maura Ferrari-Bravo MD, and Cornelius Barlascini MD
}

\begin{abstract}
BACKGROUND: Open mouthpiece ventilation is efficacious in patients with neuromuscular disease. We used this ventilation technique in patients with exacerbations of COPD with mild to moderate acidosis. METHODS: The study was performed in 2 respiratory monitoring care units. Fifty subjects with exacerbations of COPD, breathing frequency $>25, \mathrm{PaCO}_{2}>45$, and $\mathrm{pH}$ between 7.25 and 7.30, as well as Kelly scale $\leq 2$ were enrolled. Subjects were randomly assigned to receive noninvasive ventilation (NIV) via nasal mask or mouthpiece ventilation. The primary outcome was improvement in arterial blood gases. Arterial blood gases and breathing frequency were recorded $2 \mathrm{~h}$ after the start of the enrollment and then after 12, 24, and $48 \mathrm{~h}$. The duration of NIV, hospital stay, and acceptability of the interface (mouthpiece or nasal mask) using a Likert scale were assessed. RESULTS: No subjects had deterioration of gas exchange. The 2 groups had similar trends in arterial blood gases and breathing frequency. No differences in duration of NIV or hospital stay were noted. However, a significant difference in acceptability was found: subjects preferred mouthpiece ventilation $(P<.01)$. CONCLUSIONS: Open mouthpiece ventilation is a useful technique and may prevent further deterioration of gas exchange in COPD patients with mild to moderate acidosis (similar to traditional NIV delivered by a nasal mask). www.chictr.org registration ChiCTR-TRC-12002672. Key words: chronic obstructive pulmonary disease; hypercapnic respiratory failure; nasal mask; open mouthpiece ventilation; Likert scale. [Respir Care 2014;59(12):1825-1831. ( 2014 Daedalus Enterprises]
\end{abstract}

\section{Introduction}

Noninvasive ventilation (NIV) is an effective therapy to relieve dyspnea and decrease the work of breathing; it improves gas exchange in patients with acute respiratory

Dr Nicolini is affiliated with the Respiratory Medicine Unit, Hospital of Sestri Levante, Italy; Dr Santo is affiliated with the Internal Medicine Department, Hospital of Lavagna, Liguria, Italy; Dr Ferrari-Bravo is affiliated with the Hygiene and Public Health Department, Azienda Unità Sanitaria 4 Chiavarese, Liguria, Italy; Dr Barlascini is affiliated with Forensic Medicine, Azienda Unità Sanitaria 4 Chiavarese, Liguria, Italy.

The authors have disclosed no conflicts of interest.

Correspondence: Antonello Nicolini MD, Respiratory Medicine Unit, via Terzi 43-16039 Sestri Levante, Italy. E-mail: antonello.nicolini@ fastwebnet.it.

DOI: $10.4187 /$ respcare.03009 failure. It is highly effective for improving gas exchange and avoiding endotracheal intubation, especially in patients with an exacerbation of COPD. ${ }^{1}$ The rate of NIV failure remains high in observational studies (approximately $40 \%$ ) and is directly related to severity of respiratory failure. NIV has a high success rate (approximately $85 \%$ ) in mild to moderate respiratory acidosis. ${ }^{2}$ Failure

See the Related Editorial on Page 1951

can occur for several reasons, including severity of illness, poor tolerance to NIV, and inability to correct hypercapnic acidosis in the first hours of treatment. ${ }^{1,2}$ Patient tolerance can also be influenced by the shape and fit of the interface. ${ }^{3,4}$ Using different masks in the same patient can be helpful in promoting tolerance. ${ }^{3,4}$ Nasal masks are used less often than oro-nasal masks in acute respiratory failure, because the latter are considered (by some authors) faster in lowering $\mathrm{CO}_{2} \cdot{ }^{4}$ Other reasons for using different masks 
may involve patient comfort and/or economic factors. ${ }^{6} \mathrm{Few}$ clinical studies have compared the effects of different interfaces during NIV in the treatment of acute respiratory failure. ${ }^{1,4}$

The aim of this study was to compare the efficacy of nasal mask ventilation with mouthpiece ventilation in subjects with mild to moderate acidosis due to exacerbation of COPD.

\section{Methods}

\section{Setting}

The study was carried out in the respiratory and emergency medicine units of Hospital of Lavagna and Sestri Levante (Liguria, Italy) from September 2011 to December 2012. Each unit has 4 noninvasively monitored beds and admits patients with severe respiratory failure who need NIV. The study was carried out according to the Helsinki Declaration and received the approval of the institutional review committee; each subject gave written informed consent.

\section{Aim of the Study}

The goal of the study was the comparison of 2 different devices (nasal mask vs angled mouthpiece) on respiratory parameters: improvement of arterial blood gas analysis, breathing and heart rate, NIV duration, length of hospital stay, and tolerance in subjects with COPD exacerbations leading to moderate acidosis ( $\mathrm{pH} 7.30-7.25)$.

\section{Criteria for Inclusion and Exclusion}

Sixty-seven subjects (41 males and 26 females) from 66 to $79 \mathrm{y}$ of age (mean $72.6 \pm 4.3$ ) with COPD exacerbation leading to hypoxemia and moderate respiratory acidosis $\left(\mathrm{P}_{\mathrm{aCO}_{2}}>50\right.$ and arterial $\mathrm{pH}$ between 7.30 and 7.25), ${ }^{7}$ breathing frequency $\geq 25$ breaths/min, and almost normal levels of consciousness (Kelly scale $\leq 2$ ) were eligible for inclusion in the study. Diagnosis of COPD was based on the presence of air flow obstruction observed in previous pulmonary function tests and the severity of the disease according to the Global Initiative for Chronic Obstructive Lung Disease (GOLD) criteria. ${ }^{8}$ The criteria for patients' exclusion have been reported previously ${ }^{9}$ and are reported in the study protocol. Fifty patients were eligible for inclusion. Subjects' study flow chart is shown in Figure 1.

Criteria to start NIV followed clinical practice guidelines previously published: moderate to severe dyspnea, clinical signs of increased work of breathing (breathing frequency $>25$ breaths/min and use of accessory muscles of respiration), and arterial blood gases analysis showing a

\section{QUICK LOOK}

\section{Current knowledge}

Noninvasive ventilation is an effective therapy to relieve dyspnea, decrease the work of breathing, and improve gas exchange in patients with acute respiratory failure and COPD. Oro-nasal and nasal masks are most commonly used, although a wide variety of appliances are currently available. The use of mouthpiece ventilation may be attractive for improving patient comfort and reducing skin breakdown.

\section{What this paper contributes to our knowledge}

In a group of subjects with a COPD exacerbation and moderate acidosis, the use of mouthpiece ventilation resulted in similar blood gases, duration of ventilation, and stay compared with oronasal mask. Subjects expressed a statistically significant preference for mouthpiece ventilation as judged by increased comfort.

respiratory acidosis $\left(\mathrm{P}_{\mathrm{aCO}_{2}}>45 \mathrm{~mm} \mathrm{Hg}\right.$ and $\mathrm{pH}<7.35$ but $>7.25)^{7,8}$

Criteria for exclusion were: lack of spontaneous breathing, anatomical or functional airway obstruction, gastrointestinal bleeding or ileus, coma or impairment of consciousness (Kelly $>2$ ), massive agitation, massive retention of secretions, severe hypoxemia and acidosis ( $\mathrm{pH}<7.25$ ), hemodynamic instability, anatomical and or subjective difficulty gaining access to the airway, or recent upper gastrointestinal surgery.9,10 The 50 subjects who met the study criteria were randomized in 2 groups. A randomization plan was generated by a statistician not involved in the study using a computer's random number generator. The randomization was provided to the recruiting physicians in sealed envelopes.

Subjects in group A received NIV delivered via nasal mask (ComfortGel, Philips Respironics, Murrysville, Pennsylvania) with use of a chin strap only if the subject was unable to keep his/her mouth closed. Subjects in group B were treated with NIV delivered via angled mouthpiece without lip seal fixation ${ }^{11}$ (22 mm mouthpiece, Philips Respironics) (Fig. 2). A nose clip was applied. Each subject had to hold the mouthpiece firmly in the mouth to avoid leakage. Open circuit mouthpiece ventilation was applied as in a protocol previously described. ${ }^{10} \mathrm{~A}$ pressure support mode with Vivo 50 ventilator (Breas Medical, Gothenburg, Sweden) with a circuit with intentional leaks was used in the both groups.

At the start of NIV, each subject was propped up to a $45^{\circ}$ angle. The initial setting of ventilation was $10 \mathrm{~cm} \mathrm{H}_{2} \mathrm{O}$ pressure support and $5 \mathrm{~cm} \mathrm{H}_{2} \mathrm{O}$ PEEP with oxygen inspiratory flow $3 \mathrm{~L} / \mathrm{min}^{.7,9,10}$ Further adjustments were car- 


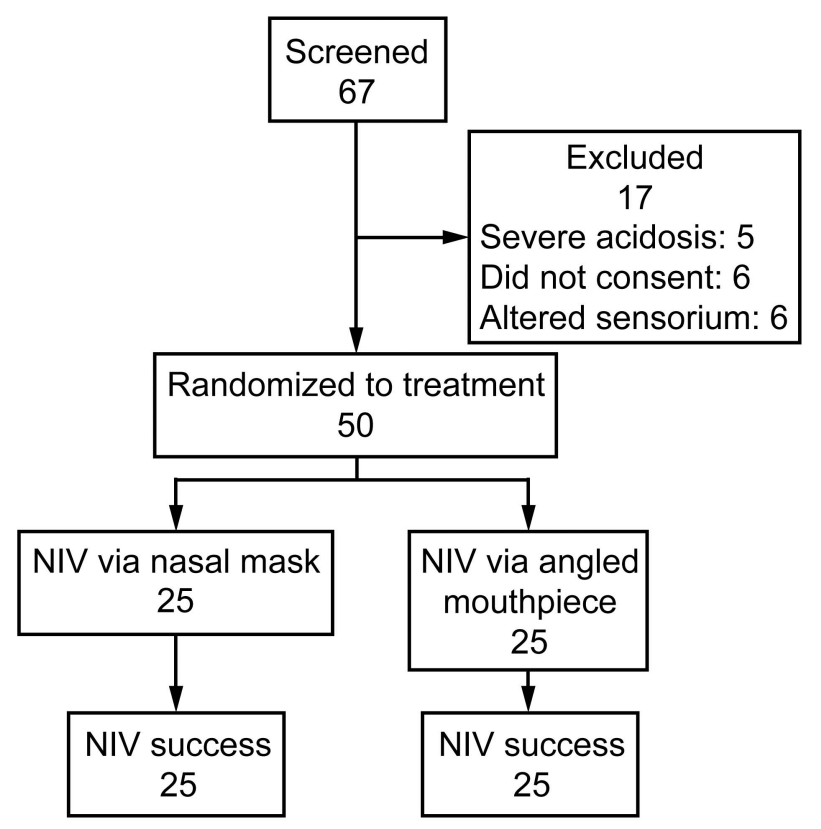

Fig. 1. Study flow chart.

ried out to achieve a tidal volume of $6-8 \mathrm{~mL} / \mathrm{kg}$ and to maintain oxygen saturation during ventilation $>90 \%$.

Parameters that were recorded at admission and after 2, 12,24 , and $48 \mathrm{~h}$ were arterial blood gases (ABGs), breathing frequency, heart rate, and dyspnea (Borg scale). After starting treatment, each subject was closely monitored for breathing frequency, heart rate, blood pressure, level of consciousness (Kelly scale), and continuous arterial oxygen saturation using pulse oximetry.

Presence of sustained clinical improvement with reduction of breathing frequency $\leq 24$ breaths $/ \mathrm{min}$ and heart rate $\leq 100$ beats/min, normal $\mathrm{pH}(\geq 7.35), \mathrm{P}_{\mathrm{aCO}_{2}}$ $\leq 55 \mathrm{~mm} \mathrm{Hg}$ and oxygen saturation $\% \geq 90$ were required to consider NIV successful. ${ }^{12}$ Subjects who deteriorated in

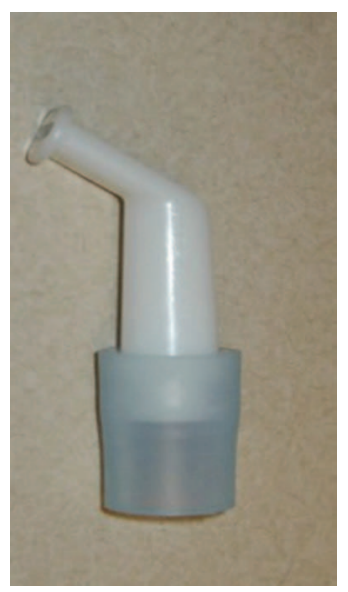

Fig. 2. The $22 \mathrm{~mm}$ angled mouthpiece used in the study. terms of ABGs (increasing $\mathrm{P}_{\mathrm{aCO}}$, decreasing $\mathrm{pH}$, level of consciousness (Kelly scale $\geq 4$ ), and/or hemodynamic instability (systolic arterial pressure $<90 \mathrm{~mm} \mathrm{Hg}$ ) within $2 \mathrm{~h}$ of starting NIV as well as those intolerant to the NIV device were dropped from the study (NIV failure). ${ }^{10}$ These subjects were evaluated for NIV with NIV platform ventilator through another device (oro-nasal mask, full face mask) or for intubation. ${ }^{10}$ Subject's discomfort and intolerance to mask or to mouthpiece was assessed using a Likert scale. ${ }^{6,13}$ Each subject was encouraged to use NIV up to $16 \mathrm{~h}$ per day. NIV was discontinued for eating and drinking; it was less frequently discontinued during the night as described in a previous protocol. ${ }^{10}$

An interlocking support system was combined with the ventilator breathing circuit during the night. The support system could be attached to various surfaces in many configurations with the use of a clamp designed for use on flat or rounded surfaces. The interlocking support circuit could be adjusted to enhance comfort and accessibility to permit mouthpiece ventilation also during sleep periods. The primary outcome of the study was the change in ABGs. The secondary outcomes were the change in cardiorespiratory parameters (breathing and heart rate), dyspnea (Borg scale), NIV duration, hospital stay, and tolerance of the device evaluated using a Likert scale. The Likert scale consists in a 5-point scale which measured the level of subject's comfort to the mask (ranging from $1=$ irrelevant to $5=$ very important). ${ }^{6}$

\section{Data Analysis}

Differences in ABGs, $\mathrm{pH}, \mathrm{P}_{\mathrm{aCO}}$, and $\mathrm{P}_{\mathrm{aO}}$ as well as breathing frequency, heart rate, and dyspnea (Borg scale) were assessed in the 2 groups. These parameters were recorded $2 \mathrm{~h}$ after enrollment, and then after 12, 24, and $48 \mathrm{~h}$ (our independent statistician used trend analysis to evaluate these parameters).

In addition, we evaluated and compared the duration of NIV and hospital stay. Acceptability of the interfaces (mouthpiece or nasal mask) was assessed using the Likert scale. Continuous variables are expressed as mean $\pm \mathrm{SD}$, and categorical variables are expressed as median with interquartile range. Frequency distributions were compared by using chi-square test and regression analysis (corrected for age and forced vital capacity) for continuous variables and Wilcoxon test for categorical variables. $P \leq .05$ was considered statistically significant. Data analysis was made with R-Project statistical software (version 2.13.2).

\section{Results}

Fifty subjects (26 males and 24 females) completed the study. The baseline characteristics of the 2 groups are shown in Table 1 . In the nasal mask group $(\mathrm{N})$, the mean 
Table 1. Baseline Characteristics of the Subjects in the Two Groups

\begin{tabular}{lccc}
\hline \hline & Nasal Mask & Mouthpiece & $P^{*}$ \\
\hline Sex $(\mathrm{M} / \mathrm{F})$ & $12 / 13$ & $14 / 11$ & .57 \\
Age $(\mathrm{y})$ & $74.3 \pm 5.3$ & $70.9 \pm 3.3$ & .03 \\
$\mathrm{FVC}(\%)^{* *}$ & $54.8 \pm 10.2$ & $47.2 \pm 8.1$ & .03 \\
$\mathrm{FEV}_{1}(\%)^{* *}$ & $27.7 \pm 2.0$ & $27.5 \pm 3.1$ & .83 \\
$\mathrm{FEV}_{1} / \mathrm{FVC}(\%)^{* *}$ & $50.9 \pm 4.6$ & $48.7 \pm 6.1$ & .21 \\
TLC $(\%)$ & $147.8 \pm 16.1$ & $145.1 \pm 14.7$ & .63 \\
RV $(\%)$ & $157.4 \pm 17.6$ & $167.6 \pm 18.7$ & .08 \\
No. of exacerbations in the & $2.3 \pm 1.4$ & $2.1 \pm 1.7$ & .10 \\
$\quad$ previous year & & & \\
Previous ICU admissions & $0.3 \pm 0.1$ & $0.25 \pm 0.2$ & .08 \\
CAT & $30.0 \pm 2.6$ & $32.2 \pm 2.6$ & .05 \\
PS (cm $\left.\mathrm{H}_{2} \mathrm{O}\right)$ & $13.5 \pm 2.2$ & $12.9 \pm 2.8$ & .28 \\
PEEP $\left(\mathrm{cm} \mathrm{H}_{2} \mathrm{O}\right)$ & $5.2 \pm 0.3$ & $4.8 \pm 0.5$ & .31
\end{tabular}

* Regression analysis (corrected for age and FVC)

** $=$ after bronchodilator.

$\mathrm{M}=$ male

$\mathrm{F}=$ female

TLC $=$ total lung capacity

$\mathrm{RV}=$ residual volume

$\mathrm{CAT}=\mathrm{COPD}$ assessment test

$\mathrm{PS}=$ pressure support

pressure support was $13.7 \pm 3.9 \mathrm{~cm} \mathrm{H}_{2} \mathrm{O}$ and PEEP was $5.2 \pm 1.7 \mathrm{~cm} \mathrm{H}_{2} \mathrm{O}$; in the mouthpiece group $(\mathrm{M})$, pressure support was $13.4 \pm 4.1$ and PEEP was $5.1 \pm 1.0 \mathrm{~cm} \mathrm{H}_{2} \mathrm{O}$.

\section{Primary Outcome}

None of the subjects presented deterioration of gas exchange in the first $2 \mathrm{~h}$. The most striking effect of NIV on the $A B G$ was noted in the first $2 \mathrm{~h}$. The differences in the $\mathrm{pH}$ and $\mathrm{P}_{\mathrm{aCO}}$ were statistically significant. The mean $\mathrm{pH}$ rose from a baseline of $7.26 \pm 0.02$ to $7.33 \pm 0.02$ in the nasal mask group $(P<.01)$ and from $7.25 \pm 0.04$ to $7.34 \pm 0.03$ in the mouthpiece group $(P<.01)$. Mean $\mathrm{P}_{\mathrm{aCO}_{2}}$ fell from a baseline value of $79.3 \pm 3.0$ to $62.8 \pm 2.9$ in the nasal mask group $(P<.01)$ and from $78.67 \pm 3.9$ to $58.8 \pm 3.6$ in the mouthpiece group $(P<.01)$. In Figure 3 , we report the trend analysis of $\mathrm{pH}, \mathrm{P}_{\mathrm{aCO}}$, and $\mathrm{P}_{\mathrm{aO}_{2}}$ for the 2 groups.

\section{Secondary Outcomes}

Together with the ABG, the other respiratory parameters (breathing frequency, heart rate, Borg scale) improved but not enough to be statistically significant (Table 2). The mean NIV duration and hospital stay were similar in the 2 groups: $79.5 \pm 10.3 \mathrm{~h}$ and $6.2 \pm 1.9 \mathrm{~d}$, respectively, in the nasal mask group and $82.4 \pm 11.9 \mathrm{~h}$ and $6.4 \pm 2.0 \mathrm{~d}$, respectively, in the mouthpiece group. Of the 25 subjects in the nasal mask group, 2 developed nasal skin breakdown.
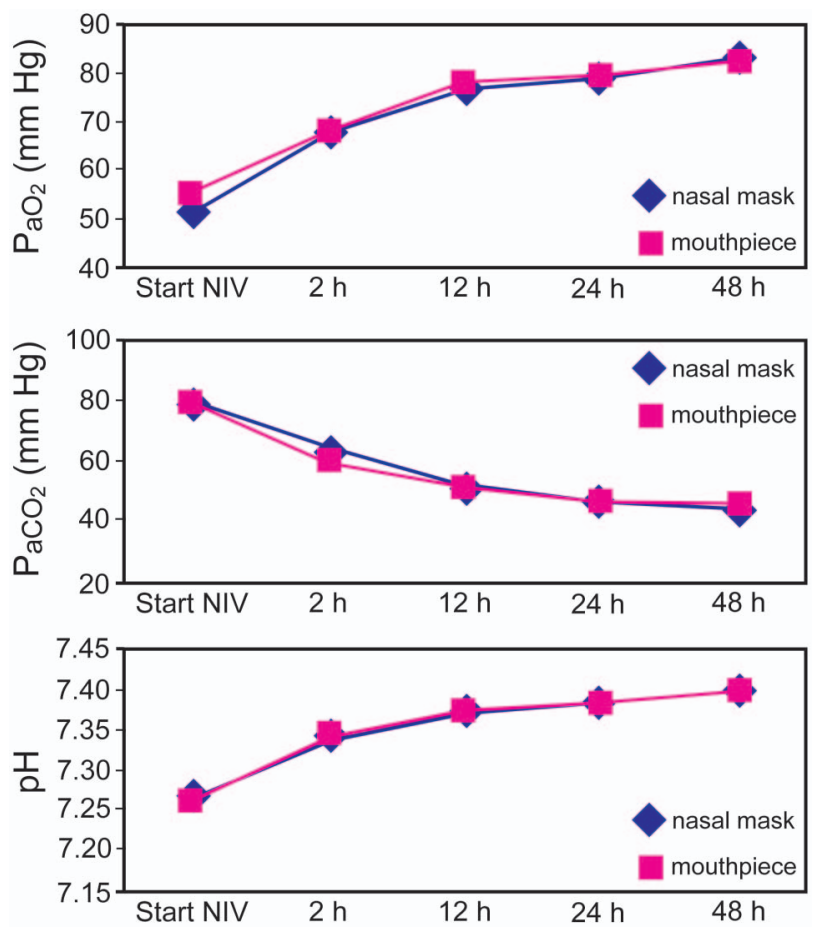

Fig. 3. Trend analysis of the 2 groups. NIV $=$ noninvasive ventilation.

Two of the 25 subjects in the mouthpiece group complained of gastric distention.

Finally, a significant difference in device acceptability (using the Likert scale) ${ }^{6,13}$ was found: the median score was $3(2-3)$ in the nasal mask group versus $4(3-4)$ in the mouthpiece group $(P \leq .01)$. The differences in the Likert score are shown in Figure 4.

\section{Discussion}

The use of NIV in patients with COPD exacerbations and respiratory acidosis $(\mathrm{pH}<7.30)$ outside ICU is well established practice. The most commonly used interfaces are oro-nasal (full face) and nasal masks. Total face mask, helmet, nasal pillow, and mouthpiece ${ }^{14-16}$ are also used. Failure of NIV is often associated with poor tolerance of the interface. Several factors such as pain, excessive pressure on facial skin, leaks, anxiety, secretions, and asynchrony between the patient and the ventilator are commonly mentioned. ${ }^{17}$ Oro-nasal masks are the most commonly used interfaces, but they may be responsible for skin damage, pain, and anxiety.4,18 Most of these disadvantages could be avoided by the use of a mouthpiece or a nasal mask. ${ }^{4,18,19}$ Mouthpiece ventilation can be considered the precursor of NIV and was tried in patients with neuromuscular diseases or severe kyphoscoliosis to improve ventilation and reduce work of breathing in the early 1950s. ${ }^{20,21}$ In COPD patients, only one study is available 
Table 2. Time Course of the Respiratory Parameters in the Two Groups

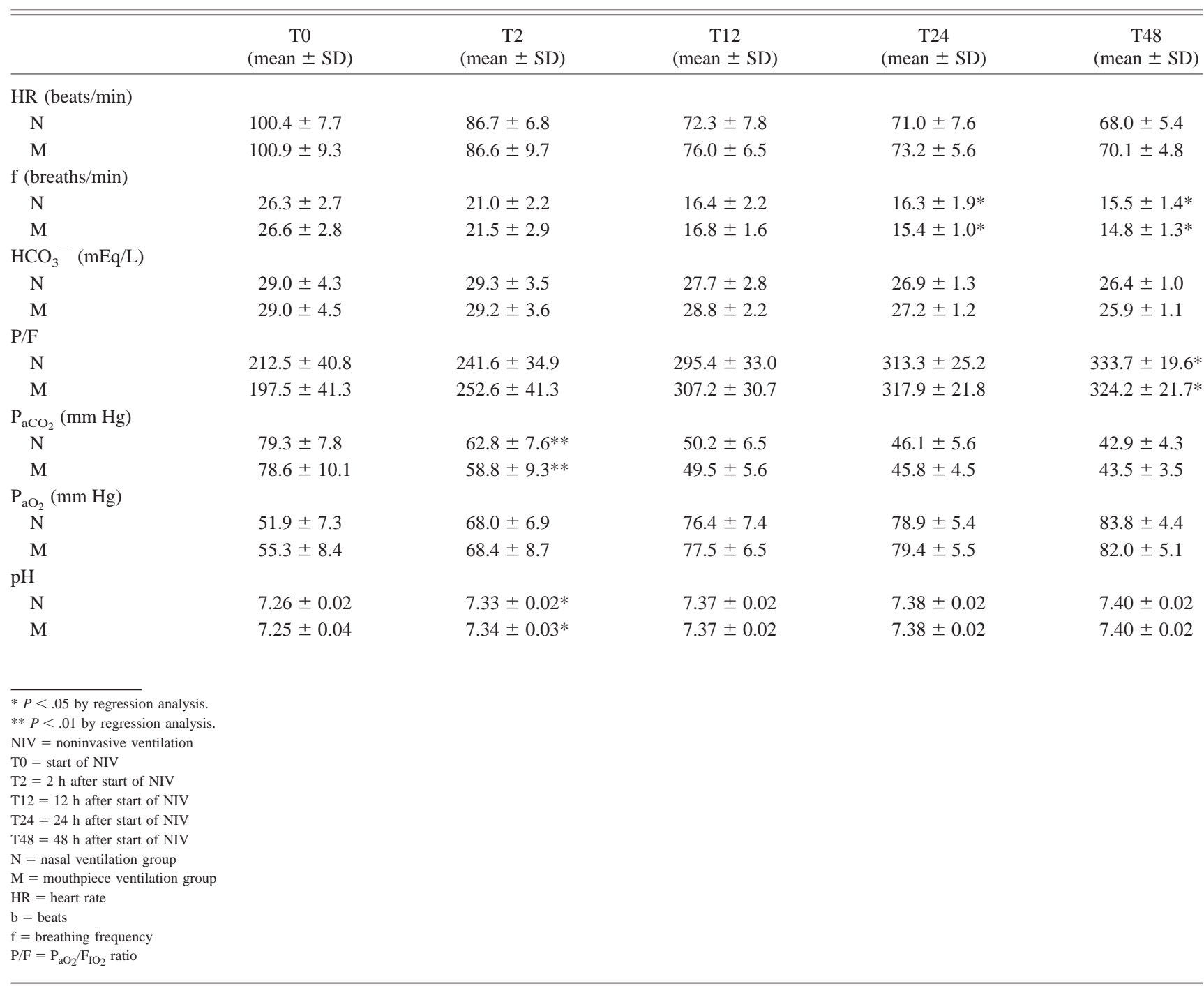

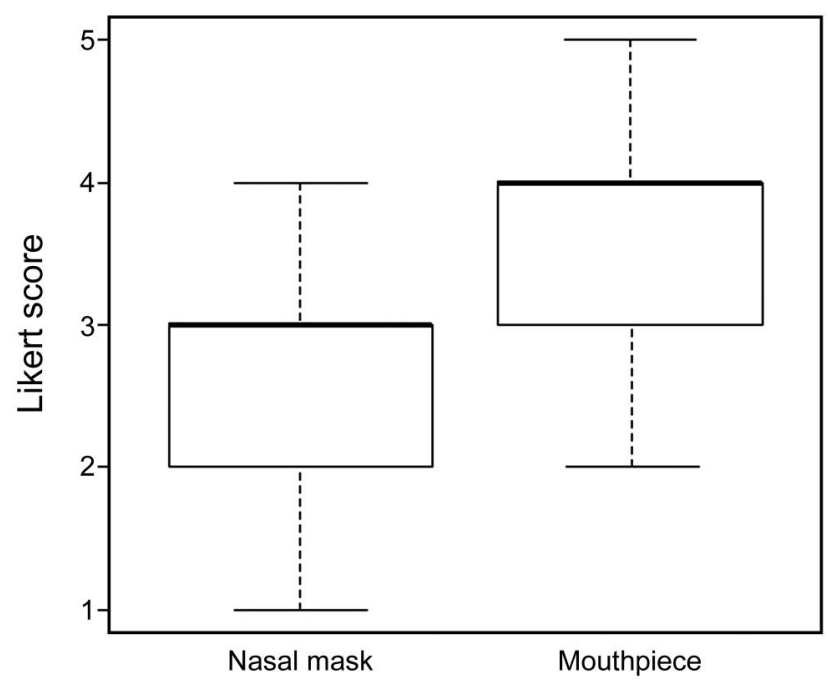

Fig. 4. Box plot showing the difference in Likert score between the 2 groups. Data are shown as median \pm interquartile range. concerning the use of NIV via mouthpiece. It demonstrated comparable results to NIV via nasal mask in terms of reduction of endotracheal intubation rate and arterial blood gas analysis. ${ }^{11}$ The benefits of nasal mask NIV as first-line treatment in COPD patients with hypercapnic respiratory failure have been widely demonstrated.22-24 Even if the improvement in blood gas analysis appeared to be very similar, confirming the comparable efficacy of these 2 ventilatory modes, the 2 approaches have certain advantages and disadvantages. NIV via mouthpiece requires a higher level of patient cooperation. The subject must keep the mouth closed to avoid air leakages. (The mouthpiece cannot be used in case of severe hypercapnic encephalopathy.) Moreover, it requires a better understanding of its strategy and technique: compliance and cooperation are necessary. Thus, a longer learning period for the patient is required. Greater nursing time and work load is 
required. ${ }^{10,17}$ Moreover, an additional increase in work load for nurses and respiratory therapists is necessary in the first hours of NIV to check the correct positioning of the nose clip and the mouthpiece of the patient to avoid air leaks. ${ }^{10}$ A nasal mask can be used also in somnolent patients (Kelly scale up to 3). It provides high levels of ventilation pressure with few leaks, requiring less cooperation. The nasal mask makes speaking, eating, and coughing difficult. ${ }^{4}$ Moreover, it requires upper airway patency. $4,10,25,26$ NIV delivered both via mouthpiece and via nasal mask reduces $\mathrm{ABG}$ parameters and respiratory parameters (breathing and heart rate, and dyspnea according to Borg scale) equally well. This study shows results similar to Glerant et al, ${ }^{10}$ which used mouthpiece ventilation in a cohort of subjects with COPD. Nasal mask and mouthpiece use produced a statistically significant lowering of $\mathrm{P}_{\mathrm{aCO}_{2}}$ and $\mathrm{pH}$ with a NIV success rate of $93.1 \%$ in the mouthpiece group.

The authors conclude their study with the statement that mouthpiece ventilation appears to be a second-line alternative to NIV delivered via a mask. We have found a higher NIV success rate, although the $\mathrm{pH}$ at admission of our subjects was lower than in the study by Glerant et $\mathrm{al}^{10}$ ( $7.27 \pm 0.09$ vs $7.29 \pm 0.04$ in the nasal mask group and $7.26 \pm 0.01$ vs $7.30 \pm 0.01$ in the mouthpiece group). These results depend on the expertise of medical and nursing staff skill. ${ }^{27,28}$

Tolerance was one of the secondary end points: mouthpiece ventilation had a greater score than nasal mask ventilation. This result was statistically significant $(P<.01)$ (in contrast to the results of the study by Schneider et al). ${ }^{17}$ In this study, which compared the tolerance of face mask versus mouthpiece for NIV, both devices could be effective; however, the comfort was decreased and the tolerance was lower for the mouthpiece. ${ }^{17}$ We are aware that oro-nasal mask is preferred mainly in the initial phase of NIV. ${ }^{9}$ It is used in between $51.6 \%$ and $67.2 \%$ of cases, whereas a nasal mask is used in $1.6-14.8 \%$ of cases. ${ }^{6}$ We have chosen to use nasal mask and mouthpiece (contrary to the unanimous agreement of most European clinicians) $)^{6}$, because they have some similar advantages and disadvantages. ${ }^{4}$

We followed the pilot study by Glerant et a ${ }^{10}$ with some differences. Our study was not carried out in an ICU, enrolled subjects with more severe symptoms, had different outcomes, and used an angled mouthpiece. This is the first study where an angled mouthpiece has been used. This appliance permits a firmer seal inside the mouth and fewer air leaks.

Our study is also the first randomized study of mouthpiece ventilation in subjects who have COPD with respiratory failure, but it has some limitations. It does not include a control group with standard medical therapy. This was not possible for ethical reasons. NIV is considered the therapy of choice for COPD exacerbations with respiratory acidosis. ${ }^{10,12,14,27}$ It would be unethical to deprive any patient of NIV, if he or she is a candidate. Ours is a referral center for patients with sleep-related respiratory disorders and neuromuscular diseases: both mouthpiece and nasal mask are widely used. Our staff has considerable experience in managing ventilation in patients with sleep disorders, with COPD, and, above all, with neuromuscular diseases using mouthpiece ventilation. Therefore, our results cannot be extrapolated to other less focused settings.

\section{Conclusions}

NIV could be considered the accepted standard modality for management of patients with exacerbations of COPD because it leads to a rapid and long lasting improvement in blood gas values and reduces intubation in this large group of patients. Oro-nasal and nasal masks are the interfaces most widely used. We have shown that the mouthpiece could represent a very useful alternative because it reduces claustrophobia, skin breakdown, and pain. Our subjects found it more comfortable. The mouthpiece should be considered as an alternative to the oro-nasal mask in moderate acidosis, especially when the mask is poorly tolerated. It should, therefore, be the second-line alternative to traditional interfaces.

\section{ACKNOWLEDGMENTS}

We are very grateful to Dr Tullio Torreggiani for his assistance in statistical analysis, and to head nurse Patrizia Bono and the nursing staff of the Department of Pulmonology, Sestri Levante Hospital (Sestri Levante, Italy) for taking outstanding care of our patients during the study.

\section{REFERENCES}

1. Fraticelli AT, Lellouche F, L'Her E, Taillé S, Mancebo J, Brochard L. Physiological effects of different interfaces during noninvasive ventilation for acute respiratory failure. Crit Care Med 2009;37(3): 939-945.

2. Confalonieri M, Garuti G, Cattaruzza MS, Osborn JF, Antonelli M, Conti $\mathrm{G}$, et al. A chart of failure risk for noninvasive ventilation in patients with COPD exacerbation. Eur Respir J 2005;25(2):348-355.

3. Gregoretti C, Confalonieri M, Navalesi P, Squadrone V, Frigerio P, Beltrame F, et al. Evaluation of patient skin breakdown and comfort with a new face mask for non-invasive ventilation: a multi-center study. Intensive Care Med 2002;28(3):278-284.

4. Nava S, Navalesi P, Gregoretti C. Interfaces and humidification for noninvasive ventilation. Resp Care 2009;54(1):71-84.

5. Benhamou D, Girault C, Faure C, Portier F, Muir JF. Nasal mask ventilation in acute respiratory failure: experience in elderly patients. Chest 1992;102(3):912-917.

6. Crimi C, Noto A, Princi P, Esquinas A, Nava S. A European survey of noninvasive ventilation practice. Eur Respir J 2010;36(2):362-369.

7. Dwarakanath A, Elliott MW. Noninvasive ventilation in the management of acute hypercapnic respiratory failure. Breathe 2013;9(5): 339-348.

8. Vestbo J, Hurd SS, Agustí AG, Jones PW, Vogelmeier C, Anzueto A, et al. Global strategy for the diagnosis, management and preven- 


\section{Mouthriece vs Nasal NIV IN COPD}

tion of chronic obstructive pulmonary disease. GOLD executive summary. Am J Respir Crit Care Med 2013;187(4):347-365.

9. Schonfer B, Kuhlen R, Neuman P, Westhoff M, Berndt C, Sitter H. Clinical practice guidelines: non-invasive ventilation as treatment of acute respitaory failure. Medicine 2008;105(24):424-433.

10. Glerant JC, Rose D, Oltean V, Dayen C, Mayeux I, Jounieaux V. Noninvasive ventilation using a mouthpiece in patients with chronic obstructive pulmonary disease and acute respiratory failure. Respiration 2007;74(6):632-639.

11. Touissant M, Chatwin M, Soudon P. Mechanical ventilation in Duchenne patients with chronic respiratory insufficiency: clinical implications of 20 years published experience. Chron Resp Dis 2007; 4(3):167-177.

12. Khilnani GC, Saikia N, Banga A, Sharma SK. Non-invasive ventilation for acute exacerbation of COPD with very high $\mathrm{PaCO}_{2}$ : a randomized controlled trial. Lung India 2010;27(3):125-130.

13. Hsu LL, Batts BK, Rau JL. Positive expiratory pressure device acceptance by hospitalized children with sickle cell disease is comparable to incentive spirometry. Respir Care 2005;50(5):624-627.

14. Hess DR. The growing role of noninvasive ventilation in patients requiring prolonged mechanical ventilation. Respir Care 2012;57(6): 900-918.

15. Pisani L, Carlucci A, Nava S. Interfaces for noninvasive mechanical ventilation: technical aspects and efficiency. Min Anest 2012;78(10): 1154-1161.

16. Girault C, Briel A, Benichou J, Hellot MF, Dachraoui F, Tamion F, Bonmarchand $\mathrm{G}$. Interface strategy during noninvasive positive pressure ventilation for hypercapnic acute respiratory failure. Crit Care Med 2009;37(1):124-131.

17. Schneider E, Dualé C, Vaille JL, Ouchchane L, Gillart T, Guelon D, et al. Comparison of tolerance of facemask vs mouthpiece for noninvasive ventilation. Anaesthesia 2006;61(1):20-23

18. Sferrazza Papa GF, Di Marco F, Akoumianaki E, Brochard L. Recent advances in interfaces for non-invasive ventilation: from bench studies to practical issues. Min Anestesiol 2012;78(10):1146-1153.
19. Hilbert G, Gruson D, Gbikpi-Benissan G, Cardinaud JP. Sequential use of noninvasive pressure support ventilation for acute exacerbation of COPD. Intensive Care Med 1997;23(9):955-961.

20. Bergofsky EH, Turino GH, Fishman AP. Cardiorespiratory failure in kyphoscoliosis. Medicine 1959;38:263-317.

21. Bach JR, Alba AS, Saporito L. Intermittent positive pressure ventilation via mouth as an alternative to tracheostomy for 257 ventilator users. Chest 1993;103(1):174-182.

22. Bott J, Carrol MP, Conway JH, Keilty SE, Ward EM, Brown EM, et al. Randomized controlled trial of nasal ventilation in acute ventilator failure due to chronic obstructive airways disease. Lancet 1993;34(8860):1555-1557.

23. Celikel T, Sungur M, Ceyhan B, Karakurt S. Comparison of noninvasive positive pressure ventilation with standard medical therapy in hypercapnic acute respiratory failure. Chest 1998; 114(6): 1636-1642.

24. Kramer N, Meyer TJ, Meharg J, Cece RD, Hill NS. Randomized prospective trial of noninvasive positive pressure ventilation in acute respiratory failure. Am J Resp Crit Care Med 1995;151(6):17991806.

25. Carrey Z, Gottfried SB, Levy RD. Ventilatory muscle support in respiratory failure with nasal positive pressure ventilation. Chest 1990;97(1):150-158.

26. Navalesi P, Fanfulla F, Frigerio P, Gregoretti C, Nava S. Physiologic evaluation of noninvasive mechanical ventilation delivered with three types of masks in patients with chronic hypercapnic respiratory failure. Crit Care Med 2000;28(6):1785-1790.

27. Coutou D, Fragnoli C, Córdoba-Izquierdo A, Boissier F, BrunBuisson C, Thille AW. Non-invasive ventilation for acute hypercapnic respiratory failure: intubation rate in an experienced unit. Resp Care 2013;58(12):2045-2052.

28. Carlucci A, Delmastro M, Rubini F, Fracchia C, Nava S. Changes in the practice of non-invasive ventilation in treating COPD patients over 8 years. Intensive Care Med 2003;29(5):419-425.

This article is approved for Continuing Respiratory Care Education credit. For information and to obtain your CRCE

(free to AARC members) visit www.rcjournal.com

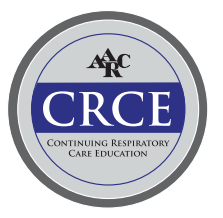

